\title{
Immunohistochemistry using a Mycobacterium tuberculosis complex specific antibody for improved diagnosis of tuberculous lymphadenitis
}

\author{
Tehmina Mustafa ${ }^{1,2,3}$, Harald G Wiker ${ }^{2}$, Sayoki GM Mfinanga ${ }^{1,4}$, Odd Mørkve ${ }^{1,5}$ and \\ Lisbet Sviland ${ }^{1,3}$ \\ ${ }^{1}$ Centre for International Health, University of Bergen, Bergen, Norway; ${ }^{2}$ Section for Microbiology and \\ Immunology, The Gades Institute, University of Bergen, Bergen, Norway; ${ }^{3}$ Department of Pathology, \\ Haukeland University Hospital, Bergen, Norway; ${ }^{4}$ National Institute for Medical Research, Muhimbili \\ Research Centre, Dar es Salaam, Tanzania and ${ }^{5}$ Department of Thoracic Medicine, Haukeland University \\ Hospital, Bergen, Norway
}

\begin{abstract}
The clinical and histological criteria used to diagnose lymphadenitis caused by Mycobacterium tuberculosis complex organisms have poor specificity. Acid-fast staining and culture has low sensitivity and specificity. We report a novel method for diagnosis of tuberculosis that uses immunohistochemistry to detect the secreted mycobacterial antigen MPT64 on formalin-fixed tissue biopsies. This antigen has not been detected in nontuberculous mycobacteria. Polymerase chain reaction (PCR) for amplification of IS6110 from DNA obtained from the biopsies was used as a gold standard. Fifty-five cases of granulomatous lymphadenitis with histologically suspected tuberculosis obtained from Norway and Tanzania were evaluated. Four known tuberculosis cases were used as positive controls, and 16 biopsies (12 foreign body granulomas and four other non-granulomatous cases) as negative controls. With immunohistochemistry, $64 \%(35 / 55)$ and with PCR, $60 \%$ $(33 / 55)$ of granulomatous lymphadenitis cases were positive. Using PCR as the gold standard, the classical tuberculosis histology had sensitivity, specificity, positive and negative predictive values of $92,37,60$, and $81 \%$, respectively, and immunohistochemistry had sensitivity, specificity, positive and negative predictive values of $90,83,86$, and $88 \%$, respectively. The observed agreement between PCR and immunohistochemistry was $87 \%$ $(\kappa=0.73)$. Immunohistochemistry with anti-MPT64 antiserum is a rapid, sensitive, and specific method for establishing an etiological diagnosis of tuberculosis in histologic specimens. Immunohistochemistry has the advantages over PCR of being robust and cheap, and it can easily be used in a routine laboratory.

Modern Pathology (2006) 19, 1606-1614. doi:10.1038/modpathol.3800697; published online 15 September 2006
\end{abstract}

Keywords: immunohistochemistry; MPT64; PCR; tuberculous lymphadenitis; diagnosis; tuberculosis

Primarily considered a pulmonary disease, tuberculosis can affect almost any organ system, with lymph node involvement being the most common form of extrapulmonary tuberculosis. ${ }^{1}$ HIV infection and other immune-compromising conditions have resulted in an increase in the incidence of tuberculous lymphadenitis. ${ }^{2-4}$ Mycobacterium tuberculosis and, to a lesser degree, Mycobacterium bovis have

Correspondence: Dr T Mustafa, MBBS, PhD, Section for Microbiology and Immunology, The Gades Institute, Haukeland University Hospital, Armauer Hansens Building, Bergen N-5021, Norway.

E-mail: tehmina.mustafa@cih.uib.no

Received 14 June 2006; revised and accepted 17 August 2006; published online 15 September 2006 previously been supposed to be the most common causative agents of tuberculous lymphadenitis. ${ }^{5}$ However, a substantial number of cases of granulomatous lymphadenitis are caused by non-tuberculous mycobacteria, especially in countries with high prevalence of these mycobacteria.$^{6-8}$

Diagnosis of tuberculous lymphadenitis is a challenge. The clinical criteria used for diagnosis have poor sensitivity and specificity and may lead to over-diagnosis, especially in countries with high endemic rates of tuberculosis. ${ }^{9}$ A diagnosis is confirmed by the presence of acid-fast bacilli and/ or isolation of M. tuberculosis in culture from biopsy specimens or fine-needle aspirates. Staining for acid-fast bacilli has low sensitivity, as its detection limit is $>10^{4}$ bacilli per slide, or $10^{4}$ bacilli per $\mathrm{ml}$ of 
specimen,,$^{10,11}$ and most cases of tuberculous lymphadenitis are paucibacillary. It does not differentiate mycobacterial species either. Mycobacterial culture takes several weeks and its sensitivity is also low in paucibacillary conditions. ${ }^{9,12-14}$ Thus, there are samples that are both acid-fast bacilli- and culture-negative. A diagnosis is therefore usually made on the basis of the classical histological changes of chronic granulomatous inflammation suggestive of tuberculosis. These histological features can be found in various conditions and diseases other than tuberculosis, and in immunocompromised tuberculosis patients the histological features can be atypical, leading to considerable difficulty and delay in diagnosis. ${ }^{15,16}$ It is not possible to differentiate between mycobacterial species on histology alone. The management of lymphadenitis caused by $M$. tuberculosis and by non-tuberculous mycobacteria differs. Surgical excision may be the only treatment required for localized cases caused by non-tuberculous mycobacteria, and for cases requiring chemotherapy, drug doses and combinations are in general higher than those recommended for tuberculosis, and there are many side effects. ${ }^{17}$ An incorrect diagnosis of tuberculosis leads to increased morbidity and mortality due to suboptimal or wrong treatment and has significant economic implications. Thus, there is a great need to develop new methods to improve the diagnostic tests for tuberculosis, and to determine the type of mycobacterium involved, for better clinical management.

Immunohistochemistry using specific antibodies has the potential to reveal any mycobacterial antigen, and the presence of an intact bacillary cell wall is not a prerequisite. Thus, immunohistochemistry is generally considered to be more sensitive than acid-fast staining and has been investigated in order to improve the diagnosis of tuberculosis, mainly by the use of a commercially available antiBacillus Calmette Guérin (BCG) antiserum (Dako), ${ }^{11,18-20}$ or in-house anti-mycobacterial antisera. ${ }^{21}$ However, immunohistochemistry has so far not been shown to be more sensitive in extrapulmonary paucibacillary cases, which are difficult to diagnose. In addition, Dako anti-BCG is not specific for mycobacteria. ${ }^{22,23}$ The ability of immunohistochemistry to distinguish between $M$. tuberculosis complex organisms (M. tuberculosis, M. bovis, $M$. bovis BCG, M. africanum, and M. microti) and nontuberculous mycobacteria has not been investigated. Recently, use of the polymerase chain reaction (PCR) for amplification of IS6110, which is specific for $M$. tuberculosis complex organisms, from formalinfixed tissue biopsies has been reported..$^{24,25}$ PCR is, however, expensive to use in a routine laboratory and is also sensitive to contamination. Immunohistochemistry has the advantages over PCR of being robust and cheap, and it can be easily used in a routine laboratory. Here we investigated the diagnostic potential of immunohistochemistry on tissue sections for specific detection of M. tuberculosis complex organisms by using an antibody to the secreted antigen MPT64 that we raised in-house. This antigen has not been detected in non-tuberculous mycobacteria. ${ }^{26,27}$ Dako anti-BCG does not contain antibodies against this antigen, as the region encoding the corresponding mpb64 gene is deleted from the Danish 1331 BCG strain used for generation of these antibodies. ${ }^{28}$ The immunohistochemistry results were compared with PCR detection of IS6110.

\section{Patients and methods}

The study was performed on lymph node biopsies from 55 cases of clinically and histologically suspected tuberculosis lymphadenitis. Table 1 shows the baseline features of patients and positive and negative controls. Twenty cases were obtained from the archives of the Department of Pathology, Haukeland University Hospital, Norway. Thirty-five cases were from patients diagnosed with mycobacterial lymphadenitis in an epidemiological study from the Mbulu, Babati, and Hanang districts in the Arusha region, Tanzania. Diagnosis was followed by treatment with a full course of antituberculosis chemotherapy. ${ }^{29,30}$ The majority of patients presented with swelling in the neck; other symptoms such as fever, pain, and weight loss were infrequent. All participants gave verbal consent to the study. Ethical clearance was obtained from ethical committees in both Tanzania and Norway.

\section{Histological Examination and Immunohistochemistry}

Parallel, 5- $\mu$ m-thick sections were prepared from formalin-fixed, paraffin-embedded biopsies. Two sections were stained with haematoxylin-eosin and Ziehl-Neelsen for acid-fast bacilli, respectively. Acid fast staining was analyzed under high power lens $(\times 40)$. Immunostaining was carried out using the EnVision + System-HRP (DakoCytomation, Denmark). Briefly, after deparaffinization and rehydration, the sections were exposed to microwave antigen retrieval using citrate buffer, $\mathrm{pH} 6.2$, at $750 \mathrm{~W}$ for $10 \mathrm{~min}$, and at $350 \mathrm{~W}$ for $15 \mathrm{~min}$. The sections were cooled for $20 \mathrm{~min}$ at room temperature and then incubated with hydrogen peroxide for 5 min. Primary antibodies-polyclonal anti-BCG (Dako) in 1:5000 dilution and anti-MPT64 (inhouse) in 1:250 dilutions-were then applied to the sections for $45 \mathrm{~min}$. These dilutions were decided upon by titration of the antisera on the positive controls and selected test blocks. This step was followed by washing and a 40-min incubation with anti-rabbit dextran polymer conjugated with horseradish peroxidase. Visualization was performed with 3-amino-9-ethylcarbazol containing $\mathrm{H}_{2} \mathrm{O}_{2}$ as substrate, applied for $10 \mathrm{~min}$. Sections were counter-stained with haematoxylin. Two negative 
Table 1 Baseline features of the study patients and controls

\begin{tabular}{|c|c|c|c|c|}
\hline & $\begin{array}{c}\text { Tanzanian cases } \\
(\mathrm{N}=35)\end{array}$ & $\begin{array}{l}\text { Norwegian cases } \\
\quad(\mathrm{N}=20)\end{array}$ & $\begin{array}{l}\text { Negative controls } \\
\quad(\mathrm{N}=16)\end{array}$ & $\begin{array}{l}\text { Positive controls } \\
\quad(\mathrm{N}=4)\end{array}$ \\
\hline \multicolumn{5}{|l|}{ Age group } \\
\hline Children (2-14 years) & 18 & 9 & 1 & \\
\hline Adults (18-86 years) & 17 & 11 & 15 & \\
\hline \multicolumn{5}{|l|}{ Gender } \\
\hline Male & 23 & 14 & 8 & \\
\hline Female & 12 & 6 & 8 & \\
\hline \multicolumn{5}{|l|}{ Origin of biopsies } \\
\hline Cervical lymph nodes & 32 & 15 & & \\
\hline Axillary lymph nodes & 1 & 2 & & \\
\hline Mesenteric lymph nodes & 1 & 1 & & \\
\hline Inguinal lymph nodes & 1 & 1 & & \\
\hline Mediastinal lymph nodes & 0 & 1 & & \\
\hline Foreign-body granulomas of the skin & & & 12 & \\
\hline Cancer & & & 2 & \\
\hline Normal tonsillar tissue & & & 1 & \\
\hline Lung tissues from autopsy of ischemic heart disease & & & 1 & \\
\hline Lung tissues from pulmonary TB with many AFBs & & & & 4 \\
\hline
\end{tabular}

controls were used, one where the primary antibody was substituted with antibody diluent and the other with an irrelevant rabbit polyclonal antibody.

\section{Antibodies}

We used in-house anti-MPT64 antibodies. These antibodies were raised by immunization of rabbits with MPT64 antigen purified from M. tuberculosis as described. ${ }^{31}$ Anti-MPT64 was absorbed with an MPT64-non-producing BCG strain to remove the crossreactive antibodies. The BCG strains were cultivated as surface pellicles on wholly synthetic Sauton liquid medium for 3 weeks at $37^{\circ} \mathrm{C}$. The bacteria were washed and disrupted by a bead beater to yield a cellular extract, and the culture medium was filtered to remove residual bacteria and concentrated by ammonium sulfate precipitation at $80 \%$ saturation. The specificity of the absorbed anti-MPT64 was tested on various purified mycobacterial antigens. These antigens were separated under reducing conditions by horizontal sodium dodecyl sulfate-polyacrylamide gel electrophoresis (SDS-PAGE) in precast 8-18\% gradient Excel gels using a Multiphor II unit 2117 (Amersham Pharmacia, Uppsala, Sweden). After separation, the proteins were transferred onto a nitrocellulose membrane (pore size, $0.2 \mu \mathrm{m}$ ) by diffusion blotting ${ }^{32}$ and the gel was stained with Coomassie brilliant blue (CBB). The membranes were blocked with PBS containing $2 \%$ bovine serum albumin and $1 \%$ gelatin and incubated with unabsorbed or absorbed anti-MPT64 antibodies for $1 \mathrm{~h}$. Bound antibodies were recognized by horseradish peroxidase-labeled anti-rabbit Ig. As substrate, 3,3diaminobenzidine was added to visualize the bound antibodies.

\section{DNA Extraction and Nested PCR for IS6110}

From each paraffin-embedded tissue block, three to six $10-\mu \mathrm{m}$-thick sections were cut and placed in a sample preparation tube. To prevent carryover tissue contamination of the samples, the microtome blade was cleaned with xylene or $100 \%$ ethanol after sectioning each sample. Each case was tested in triplicate. Proteinase $\mathrm{K}$ digestion of the tissue sections was performed by using the MagAttract ${ }^{\circledR}$ DNA Mini M48 kit (Qiagen, West Sussex, UK). The protocol provided with the kit was modified. An increase in incubation time with proteinase $\mathrm{K}$ to $48 \mathrm{~h}$ enhanced the mycobacterial DNA yield. Fresh proteinase $\mathrm{K}$ was added after $24 \mathrm{~h}$. Sonication of the samples for mycobacterial cell lysis after $24 \mathrm{~h}$ of incubation had no effect on mycobacterial DNA extraction. DNA isolation was performed using a BioRobot M48 (Qiagen). The purified DNA was suspended in $50 \mu \mathrm{l}$ of sterile deionized water. $M$. tuberculosis complex-specific DNA was amplified by nested PCR for the IS6110 sequence. For the first PCR, $5 \mu \mathrm{l}$ of DNA extracted from each sample was added to $45 \mu \mathrm{l}$ of a PCR reaction mixture containing $25 \mu$ l of HotStarTaq master mix (Qiagen) (2.5 units of HotStarTaq DNA polymerase, $1 \times$ PCR buffer, and $200 \mu \mathrm{M}$ of each dNTP), $0.25 \mu \mathrm{l}$ of each $100 \mu \mathrm{M}$ primer stock solution, and distilled water to a final volume of $50 \mu \mathrm{l}$. For the second PCR, $1 \mu \mathrm{l}$ of the first PCR product was used as template. The primer sequences and PCR programs are described in Table 2. PCR products were analyzed using $3 \%$ NuSieve agarose gels. All testing was performed as generally recommended in the guidelines for molecular diagnostic methods, with unidirectional workflow and physical separation of reagent preparation, amplification, and product detection procedures. The control samples included defined positive and 
Table 2 Primer sequences and PCR programs used

\begin{tabular}{lll}
\hline Primers & Product size & Parameters $^{\mathrm{a}}$ \\
\hline 1st PCR & $123 \mathrm{bp}$ & $94^{\circ} \mathrm{C}, 1 \mathrm{~min}$ \\
5'CCTGCGAGCGTAGGCGTCGG3' $^{\prime}$ & & $68^{\circ} \mathrm{C}, 1 \mathrm{~min}$ \\
5'CTCGTCCAGCGCCGCTTCGG3 $^{\prime}$ & & $72^{\circ} \mathrm{C}, 20 \mathrm{~s}$ \\
& $92 \mathrm{bp}$ & $94^{\circ} \mathrm{C}, 1 \mathrm{~min}$ \\
Nested PCR & & $58^{\circ} \mathrm{C}, 1 \mathrm{~min}$ \\
5'TTCGGACCACCAGCACCTAA3' $^{\prime}$ & & $72^{\circ} \mathrm{C}, 20 \mathrm{~s}$ \\
5'TCGGTGACAAAGGCCACGTA3 $^{\prime}$ & & 35 \\
\hline
\end{tabular}

${ }^{\mathrm{a}} \mathrm{An}$ initial activation step of heating at $95^{\circ} \mathrm{C}$ for $15 \mathrm{~min}$ and a final extension at $72^{\circ} \mathrm{C}$ for $10 \mathrm{~min}$ was used for all PCR amplifications.

negative formalin-fixed, paraffin-embedded tissues processed in an identical manner and under the same conditions as the test samples. Additional negative controls included DNA extraction controls with all the tissue digestion, DNA extraction, and PCR steps but without any tissue. For PCR negative controls, DNA template was substituted with distilled water; $M$. tuberculosis DNA isolated from bacterial cultures was used as the positive control.

\section{Confirmation of Amplification Specificity}

The specificity of the 92-bp nested PCR product was confirmed by direct sequencing. The PCR products were purified using the ExoSap-IT clean-up method. Briefly $5 \mu \mathrm{l}$ of PCR products were mixed with $2 \mu \mathrm{l}$ of ExoSap-IT solution and treated for $15 \mathrm{~min}$ at $37^{\circ} \mathrm{C}$, then the enzymes inactivated by heating at $80^{\circ} \mathrm{C}$ for $15 \mathrm{~min}$, followed by cooling at $4^{\circ} \mathrm{C}$. The sequencing solution was prepared by using a BigDye Terminator v1.1 Cycle sequencing Kit (Applied Biosystems, California, USA). A final volume of $10 \mu \mathrm{l}$ was made up by adding $3.5 \mu \mathrm{l}$ of $\mathrm{ddH}_{2} \mathrm{O}, 1.5 \mu \mathrm{l}$ of $5 \times$ BigDye buffer, $1 \mu \mathrm{l}$ of BigDye, $0.8 \mu \mathrm{l}$ of $2.5 \mu \mathrm{M}$ primers, and $3.2 \mu \mathrm{l}$ of cleaned PCR products. The cycle-sequencing reaction was incubated at $96^{\circ} \mathrm{C}$ for $5 \mathrm{~min}$, followed by 25 cycles of denaturation at $96^{\circ} \mathrm{C}$ for $10 \mathrm{~s}$, annealing at $55^{\circ} \mathrm{C}$ for $5 \mathrm{~s}$ and extension at $60^{\circ} \mathrm{C}$ for $4 \mathrm{~min}$. The reaction mixture was then cooled to $4^{\circ} \mathrm{C}$. Automatic sequencing was performed on an ABI PRISM 310 genetic analyzer (Applied Biosystems).

\section{Results}

\section{Histology, Staining for Acid-Fast Bacilli, and Culture}

Both necrotic and non-necrotic granulomas with epithelioid cells and multinucleated giant cells characteristic of tuberculosis were observed in these patients. Necrotic granulomas were found in $75 \%$ of the patients, whereas $25 \%$ had both necrotic and non-necrotic granulomas. There were no differences in histology between the Norwegian and Tanzanian patients. With Ziehl-Neelsen staining only two Norwegian cases were positive, with very few bacilli, and all the Tanzanian cases were negative.
Among the 19 Tanzanian cases for which culture results were available, only one was culture-positive. No culture results were available for the Norwegian cases.

\section{Immunohistochemistry}

Immunohistochemistry with Dako anti-BCG antibodies stained the four positive controls, but none of the lymphadenitis cases or the negative controls. The initial experiments with the anti-MPT64 antiserum indicated that there was some crossreactivity, as five of 16 negative controls were positive. To enhance the specificity, the antiserum was absorbed with antigen extracts of MPT64-non-producing BCG strains, which resulted in total removal of signal from two samples (foreign-body granulomas), and partial reduction in the other two (also foreign-body granulomas) of these five 'false-positive' controls. The effect of absorption on the staining of a biopsy from a foreign-body granuloma is shown (Figure 1a and b). Absorption of the antiserum enhanced the specificity but did not affect the sensitivity, as there was no difference in the staining of positive controls (Figure 1c and d). The effect of absorption was also demonstrated by Western blotting with antigens from M. tuberculosis, purified MPT64, and MPT64 producer and non-producer BCG strains. Reactivity with components other than MPT64 disappeared after absorption (Figure 2). Absorption of the antiserum with BCG extracts seemed to be specific for reduction of crossreactivity, as absorption with five other bacterial lysates (Escherichia coli, Enterococcus faecalis, Staphylococcus epidermidis, Staphylococcus aureus, and alpha-hemolytic streptococcus) had no additional effect on the specificity.

With absorbed anti-MPT64 antibodies, 95\% (19/ $20)$ and $46 \%(16 / 35)$ of the cases were positive in the Norwegian and Tanzanian material, respectively (Table 3). The MPT64 antigen was detected as granular cytoplasmic staining in the positive controls (Figure 1c and d) and in granuloma cells in the tuberculosis cases (Figure 3). The surrounding normal-looking tissues in the tuberculous lymph nodes did not show staining. Within granulomas, antigen was mainly detected in the epithelioid cells and giant cells. Necrotic centers were negative in the 

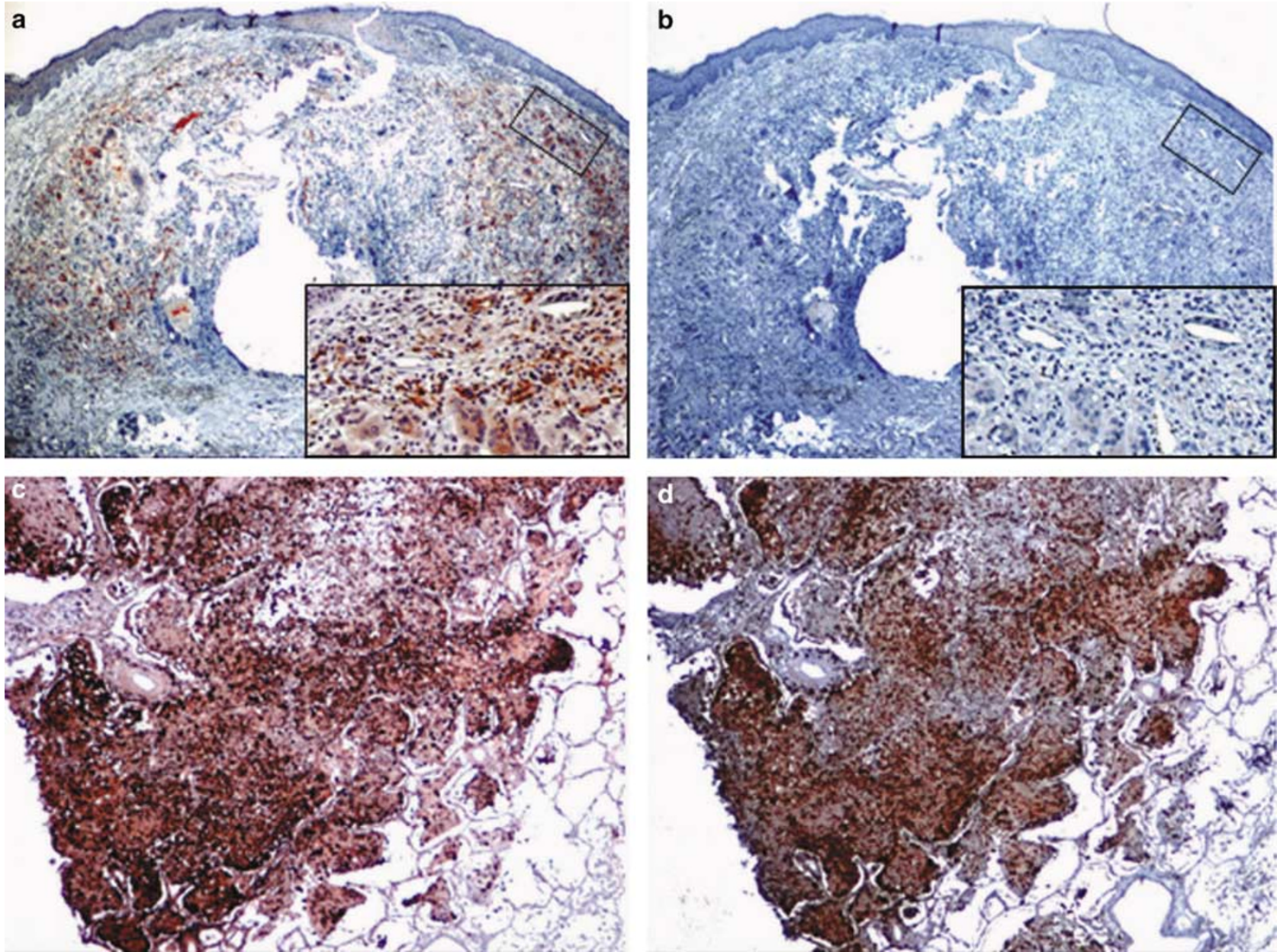

Figure 1 Biopsy from a foreign-body granuloma (a and $\mathbf{b}$ ) and heavily $M$. tuberculosis-infected lung tissue (c and d), stained with unabsorbed (a and c) and absorbed anti-MPT64 antiserum (b and d) by using immunohistochemistry. Insets in (a) and (b) show magnified images of the marked areas. Staining of negative controls with unabsorbed anti-MPT64 serum disappeared upon absorption, whereas there was no effect on the MPT64-specific staining in the positive controls.

majority of cases (Figure 3). The intensity and extent of staining varied. In some, most of the cells in the granulomas were strongly positive, while in others only a few cells showed strong or moderate intensity. Any positive signal was recorded. Differences in the staining intensity or pattern of staining could not be explained on the basis of patient's clinical information or histology. All the positive controls were positive, whereas three of the 16 negative controls (two foreign body granulomas and one tumor) were also positive.

\section{Polymerase Chain Reaction}

With PCR, $85 \%(17 / 20)$ and $46 \%(16 / 35)$ of the cases were positive in the Norwegian and Tanzanian material, respectively (Table 3). Most of the samples were positive upon nested PCR only, including 13 of 17 Norwegian cases and 15 of 16 Tanzanian cases. In some cases, all three samples from one case were positive whereas in others only one or two among the triplicates were positive (Figure 4). All the positive controls were positive, whereas three of the 16 negative controls (two foreign-body granulomas and one tumor) were also positive.

The results with immunohistochemistry and PCR were reproducible, as tested by repeating the immunohistochemistry on all cases and PCR on six of the cases and controls. There were no differences between the positive staining with MPT64 and PCR with respect to age and gender. In order to confirm the specificity of PCR for the detection of $M$. tuberculosis complex organisms, a selected number of cases and controls (four granulomatous lymphadenitis cases, four positive controls, and one tumor negative control) were sequenced. All the amplified sequences were IS6110 of the $M$. tuberculosis complex.

\section{Validation of Immunohistochemistry as a Diagnostic Test}

Classical tuberculosis histology cannot differentiate between mycobacterial species. This became evi- 


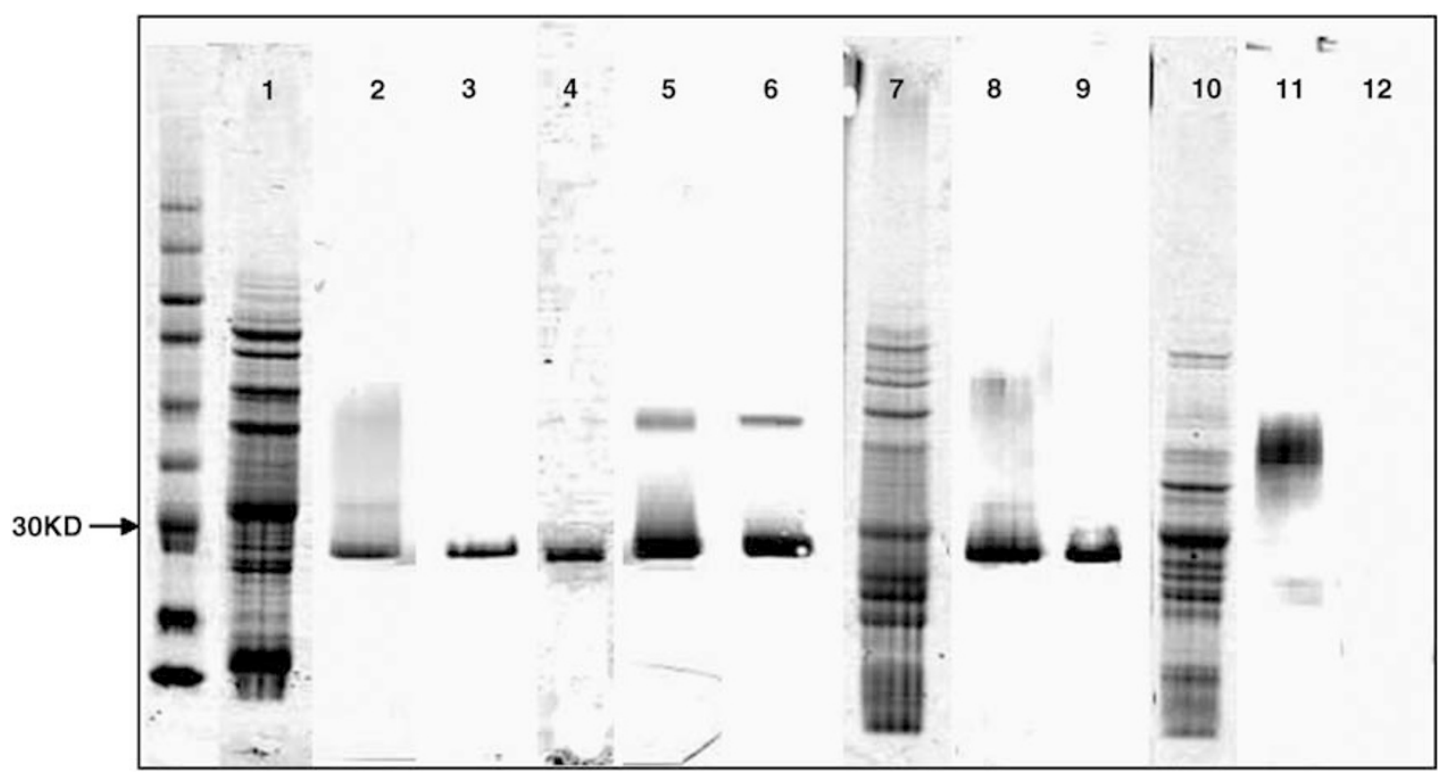

Figure 2 SDS-PAGE analysis with Western blotting. Left lane: molecular mass marker; lanes 1-3: culture filtrate of a clinical isolate of $M$. tuberculosis $(20 \mu \mathrm{g})$; lanes 4-6: purified MPT64 antigen (1 $\mu \mathrm{g})$; lanes 7-9: culture filtrate of an MPT64-producing BCG strain (20 $\mu \mathrm{g})$; lanes 10-12: culture filtrate of an MPT64-non-producing BCG strain (20 $\mu \mathrm{g})$. Lanes 1, 4, 7, and 10: gel stained with CBB. Lanes 2, 5, 8, and 11: nitrocellulose membrane probed with unabsorbed polyclonal rabbit anti-MPT64 antibodies. Lanes 3, 6, 9, and 12: membrane developed with absorbed polyclonal rabbit anti-MPT64 antibodies. The staining of crossreactive antigens disappeared after absorption.

Table 3 Comparison of detection of $M$. tuberculosis complex with immunohistochemistry and with PCR

\begin{tabular}{lrr}
\hline Anti-MPT64 & \multicolumn{2}{c}{ PCR } \\
\cline { 2 - 3 } & Positive & Negative \\
\hline Norwegian cases & 17 & 2 \\
$\quad$ Positive & 0 & 1 \\
$\quad$ Negative & & \\
Tanzanian cases & 14 & 2 \\
$\quad$ Positive & 2 & 17 \\
$\quad$ Negative & & \\
$\quad$ Positive controls & 4 & 0 \\
$\quad$ Positive & 0 & 2 \\
$\quad$ Negative & & 11 \\
Negative controls & 1 & 35 \\
$\quad$ Positive & 2 & \\
$\quad$ Negative & 40 & \\
Total & & \\
\hline
\end{tabular}

The observed agreement between the two tests was $87 \%$, with $\kappa$ of 0.73 .

dent when histological changes typical of tuberculosis were validated as the diagnostic test to detect M. tuberculosis complex organisms by using PCR as the gold standard. Among the Norwegian cases, the sensitivity and specificity of histology were 85 and $81 \%$, respectively, and the positive and negative predictive values were 85 and $81 \%$, respectively. Among the Tanzanian cases, the sensitivity was $84 \%$, but the specificity was reduced to $41 \%$. The positive predictive value was as low as $46 \%$. The negative predictive value was $81 \%$. Overall, in the combined Tanzanian and Norwegian populations, the sensitivity, specificity, positive and negative predictive values were $92,37,60$, and $81 \%$ respectively.

The diagnostic validity of immunohistochemistry with MPT64 for M. tuberculosis complex organisms by using PCR as the gold standard gave promising results (Table 3). Among Norwegian cases, the sensitivity was $100 \%$. The specificity was $33 \%$, but this was based on only one of three cases. The positive and negative predictive values were 90 and $100 \%$, respectively. Among Tanzanian cases the sensitivity and specificity were 88 and $90 \%$, respectively, and the positive and negative predictive values were 88 and $90 \%$, respectively. Overall, in the combined Tanzanian and Norwegian populations, including the positive and negative controls, the sensitivity, specificity, and positive, and negative predictive values were $90,83,86$, and $88 \%$, respectively. Table 3 shows the agreement between the two tests. The observed agreement was $87 \%$, with $\kappa$ of 0.73 . Immunohistochemistry for MPT64 is therefore a highly reliable method for detecting M. tuberculosis complex organisms.

\section{Discussion}

This is the first study to investigate the in vivo expression of MPT64 for diagnostic purposes in tissue biopsies. The antigens of tubercle bacilli expressed after in vitro culture of the organism on 

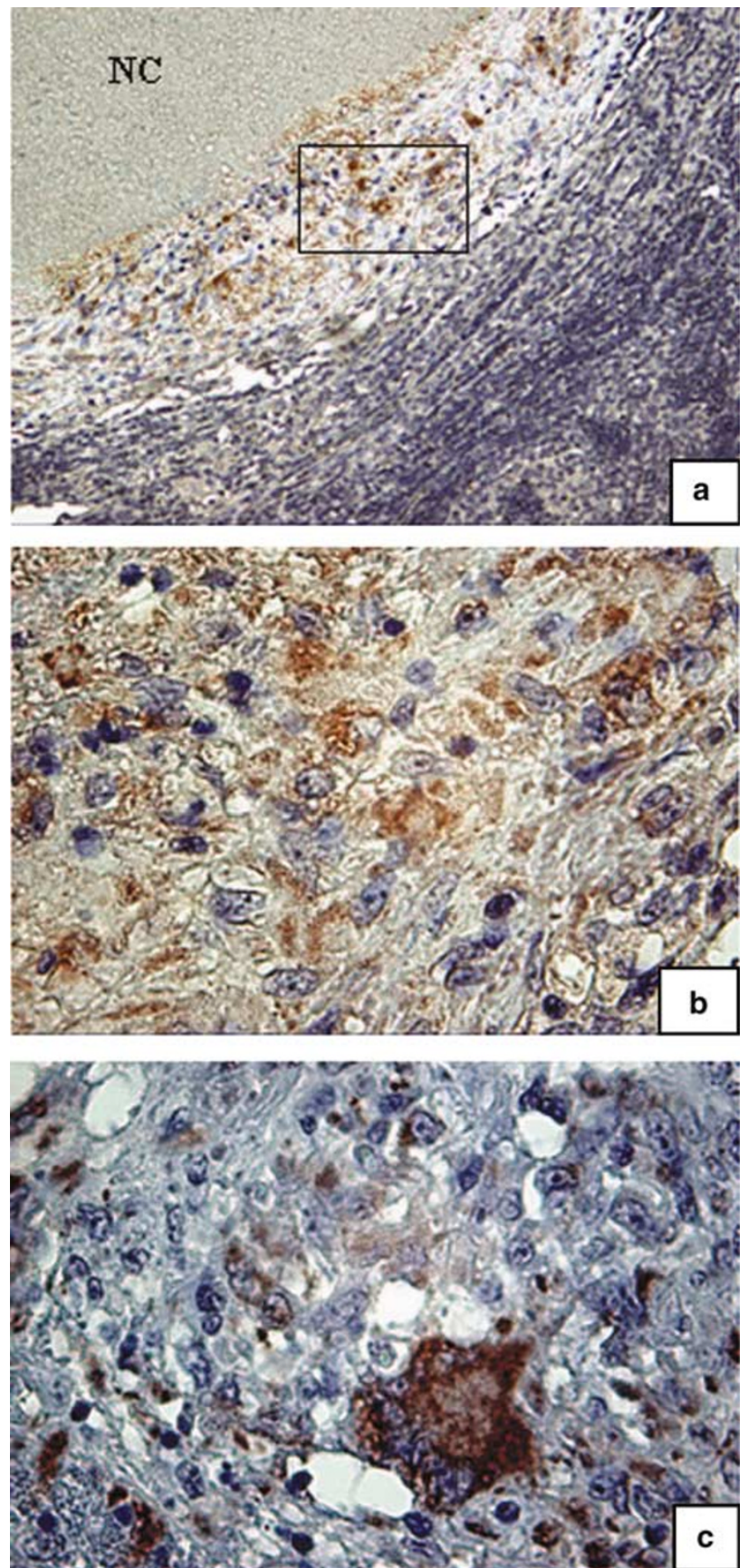

Figure 3 The staining pattern of MPT64-positive cells in tuberculosis cases as detected by immunohistochemistry. (a) MPT64 expressed in a tuberculous lymphadenitis case from Norway. Antigen was mainly seen in the epithelioid and giant cells and not in the necrotic centers (NC). The surrounding lymph node tissue was negative. (b) The marked area in (a) shown at higher magnification. (c) A representative area from the granuloma showing a multinucleated giant cell with strong staining for MPT64.

synthetic media are relatively well known, whereas the in vivo expression pattern has not been extensively studied. This study showed that both immunohistochemistry with anti-MPT64 antiserum and PCR for IS6110 are sensitive and specific

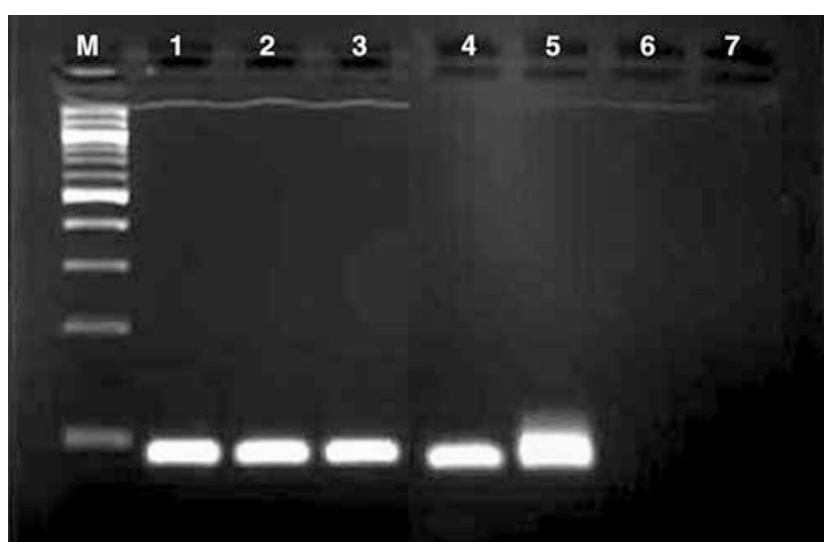

Figure 4 PCR amplification of a 92-bp fragment of IS6110. Lane M: 100-bp ladder; lanes 1-3: triplicates from a tuberculous lymphadenitis case; lane 4: tissue positive control; lane 5: DNA from $M$. tuberculosis H37Rv; lane 6: DNA extracted from a tissue negative control; lane 7: negative PCR control. Most of the cases were positive on nested PCR. In some cases all three samples (lanes 1-3) were positive, whereas in others only one or two of the triplicate samples were positive.

methods for establishing a diagnosis of tuberculosis in routinely processed, formalin-fixed, paraffinembedded histological specimens.

In the positive controls, immunohistochemistry with Dako anti-BCG gave positive signals in areas where acid-fast staining was negative, indicating that it is more sensitive than acid-fast staining in multibacillary cases. This has also been shown by others. ${ }^{11,20,21}$ Among the acid-fast bacilli-negative lymphadenitis cases, immunohistochemistry with Dako anti-BCG was negative and not more sensitive than acid-fast staining. In contrast, MPT64 was demonstrated in the majority of cases. It is important to note that Dako anti-BCG does not contain antiMPT64 antibodies. The findings indicate that MPT64 may be unique in this respect of in vivo expression.

It is difficult to explain the positive staining and PCR in three of the 16 negative controls. These were foreign-body granulomas and one malignant tumor in patients from Norway. The tumor was positive with both immunohistochemistry and PCR. The patient was 60 years old and the possibility of latent tuberculosis infection or reactivation cannot be excluded. PCR can be positive in latently infected individuals. ${ }^{33}$ In the two foreign-body granuloma controls that were positive on PCR, from adults aged 31 (weak positive on PCR) and 57 years from Norway, explanation on the basis of latent tuberculosis infection is unlikely, though not impossible. Foreign-body granulomas are well known for giving nonspecific staining by immunohistochemistry, and the positive results in two such negative controls were most likely due to residual irrelevant antibodies in the absorbed anti-MPT64 reagent. Absorption reduced the signal in these controls-an observation that supports this conclusion. 
All the Tanzanian lymphadenitis patients were originally diagnosed as tuberculosis and given treatment accordingly. In retrospect, in only $45 \%$ of the cases was the disease shown to be caused by M. tuberculosis complex. ${ }^{9}$ Over-diagnosis of tuberculous lymphadenitis with subsequent over-treatment represents a general problem, especially in high-endemic countries, and results in incorrect use of chemotherapy and increased morbidity, with possible serious economic consequences. The high specificity and sensitivity of immunohistochemistry for MPT64 may help to reduce this problem. The lower number of $M$. tuberculosis complex positive cases in the Tanzanian material compared with the Norwegian material could be explained by the prevalence of non-tuberculous mycobacteria in the environment. ${ }^{34}$ An epidemiological study from Tanzania, where these samples were taken, showed that half of the culture positive cases were caused by non-tuberculous mycobacteria and that they were as common as M. tuberculosis in granulomatous lymph adenitis. ${ }^{8}$ In recent years, environmental mycobacterial disease have become particularly relevant to human health, due to their high prevalence in HIVcoinfected patients. ${ }^{35}$ Considering these facts, infection with non-tuberculous mycobacteria is a public health issue, making it important to differentiate between mycobacterial species in granulomatous infections.

Mycobacterial culture is generally used as a gold standard for the validation of any new diagnostic test. However, tuberculosis cultures are often unavailable when archival material is studied, as many tissues studied histologically are not concurrently cultured for tuberculosis. Furthermore, culture is positive in only a fraction of lymphadenitis cases. ${ }^{8}$ Low culture positivity in extrapulmonary tuberculosis is well known and represents a general problem. This makes it problematic to use culture results as a gold standard for a test that is validated for paucibacillary tuberculosis lymphadenitis cases. In addition, mycobacterial culture does not differentiate between tuberculous and non-tuberculous mycobacteria either, unless specific tests are performed. PCR has been shown to have sensitivity ranging from 75 to $100 \%$ and specificity of 99 to $100 \%$, by other studies using culture as the gold standard. ${ }^{36,37}$ Accordingly, we used PCR as the gold standard for the detection of $M$. tuberculosis complex organisms in the causation of lymphadenitis.

In conclusion, immunohistochemistry with antiMPT64 antiserum and PCR are rapid, sensitive, and specific methods for establishing an etiological diagnosis of tuberculosis using formalin-fixed, paraffin-embedded histologic specimens. Immunohistochemistry has the advantages over PCR of being robust, quicker, and cheaper, and it can be used in high-endemic countries. We therefore recommend using a combination of acid-fast staining and immunohistochemistry with MPT64 to establish a diagnosis of tuberculosis. This method could be adopted for use on smears obtained from fluids and fine-needle aspirates from various extrapulmonary tuberculosis sites and this is currently being investigated in our laboratory.

\section{Acknowledgements}

We thank Kalaiarasy Kugarajh for excellent technical assistance. This study was supported by funds from the University of Bergen, from Norwegian health-related research funding agency; Helse-Vest, and Norwegian trusts for research-funding; Gades Legat, Connie Gulberg Jansens Legat, and Skipsreder Tom Wilhelmsens Stiftelse. Section of Pathology, the Gades Institute, University of Bergen has provided laboratory facilities for part of this study.

\section{References}

11989 Tuberculosis Statistics in United States. Report, US Department of Health and Human Services, Public Health Services, Centres for Disease Control, Atlanta, GA, 1991.

2 Small PM, Schecter GF, Goodman PC, et al. Treatment of tuberculosis in patients with advanced human immunodeficiency virus infection. $\mathrm{N}$ Engl J Med 1991;324:289-294

3 Range N, Ipuge YA, O’Brien RJ, et al. Trend in HIV prevalence among tuberculosis patients in Tanzania, 1991-1998. Int J Tuberc Lung Dis 2001;5:405-412.

4 van den Broek J, Mfinanga S, Moshiro C, et al. Impact of human immunodeficiency virus infection on the outcome of treatment and survival of tuberculosis patients in Mwanza, Tanzania. Int J Tuberc Lung Dis 1998;2:547-552.

5 Kidane D, Olobo JO, Habte A, et al. Identification of the causative organism of tuberculous lymphadenitis in Ethiopia by PCR. J Clin Microbiol 2002;40:4230-4234.

6 Evans MJ, Smith NM, Thornton CM, et al. Atypical mycobacterial lymphadenitis in childhood-a clinicopathological study of 17 cases. J Clin Pathol 1998;51: 925-927.

7 Ginsburg CM. Nontuberculous mycobacterial infections. Pediatr Infect Dis J 1992;11:875-877.

8 Mfinanga SG, Morkve O, Kazwala R, et al. Mycobacterial adenitis: role of Mycobacterium bovis, non-tuberculous mycobacteria, HIV infection, and risk factors in Arusha, Tanzania. East Afr Med J 2004;81:171-178.

9 Mfinanga SG, Morkve O, Sviland L, et al. Patient knowledge, practices and challenges to health care system in early diagnosis of mycobacterial adenitis. East Afr Med J 2005;82:173-180.

10 Yeager Jr H, Lacy J, Smith LR, et al. Quantitative studies of mycobacterial populations in sputum and saliva. Am Rev Respir Dis 1967;95:998-1004.

11 Ulrichs T, Lefmann K, Reich M, et al. Modified immunohistological staining allows detection of Ziehl-Neelsen-negative Mycobacterium tuberculosis organisms and their precise localization in human tissue. J Pathol 2005;205:633-640.

12 Daniel TM. The rapid diagnosis of tuberculosis-a selective review. J Lab Clin Med 1990;116:277-282. 
13 Mishra A, Singhal A, Chauhan DS, et al. Direct detection and identification of Mycobacterium tuberculosis and Mycobacterium bovis in bovine samples by a novel nested PCR assay: Correlation with conventional techniques. J Clin Microbiol 2005;43:5670-5678.

14 Hans LR, Chonde TM, Myking H. The Public Health Service National Tuberculosis Reference Laboratory and the National Laboratory Network, Report. IUTLD: Paris, 1998, pp 1-110.

15 Lucas SB, Nelson AM. Pathogenesis of tuberculosis in human immunodeficiency virus-infected people. In: Bloom BR (ed). Tuberculosis: Pathogenesis, Protection and Control. ASM Press: Washington, DC, 1994, pp 503-513.

16 Muller H, Kruger S. Immunohistochemical analysis of cell composition and in situ cytokine expression in HIV- and non-HIV-associated tuberculous lymphadenitis. Immunobiology 1994;191:354-368.

17 Katoch VM. Infections due to non-tuberculous mycobacteria (NTM). Indian J Med Res 2004;120:290-304.

18 Mustafa T, Phyu S, Nilsen R, et al. A mouse model for slowly progressive primary tuberculosis. Scand J Immunol 1999;50:127-136.

19 Higuchi S, Suga M, Dannenberg AM, et al. Persistence of protein, carbohydrate and wax components of Tubercle-Bacilli in dermal Bcg lesions. Am Rev Respir Dis 1981;123:397-401.

20 Wiley EL, Mulhollan TJ, Beck B, et al. Polyclonal antibodies raised against Bacillus Calmette-Guerin, Mycobacterium duvalii, and Mycobacterium paratuberculosis used to detect mycobacteria in tissue with the use of immunohistochemical techniques. Am J Clin Pathol 1990;94:307-312.

21 Humphrey DM, Weiner MH. Mycobacterial antigen detection by immunohistochemistry in pulmonary tuberculosis. Hum Pathol 1987;18:701-708.

22 Kutzner H, Argenyi ZB, Requena L, et al. A new application of BCG antibody for rapid screening of various tissue microorganisms. J Am Acad Dermatol 1998;38:56-60.

23 Geisel O, Netter F, Hermanns W. Specificity of the immunohistochemical demonstration of mycobacterial antigens. J Veterinary Med Ser B 1994;41:548-553.

24 Zink AR, Nerlich AG. Molecular strain identification of the Mycobacterium tuberculosis complex in archival tissue samples. J Clin Pathol 2004;57:1185-1192.

25 Azov AG, Koch J, Hamilton-Dutoit SJ. Improved diagnosis of mycobacterial infections mi formalin- fixed and paraffin-embedded sections with nested polymerase chain reaction. APMIS 2005;113:586-593.

26 Harboe M, Nagai S, Patarroyo ME, et al. Properties of proteins Mpb64, Mpb70, and Mpb80 of Mycobacterium-Bovis Bcg. Infect Immun 1986;52:293-302.

27 Elhay MJ, Oettinger T, Andersen P. Delayed-type hypersensitivity responses to ESAT-6 and MPT64 from Mycobacterium tuberculosis in the guinea pig. Infect Immun 1998;66:3454-3456.

$28 \mathrm{Li} \mathrm{H}$, Ulstrup JC, Jonassen TO, et al. Evidence for absence of the MPB64 gene in some substrains of Mycobacterium bovis BCG. Infect Immun 1993;61: 1730-1734.

29 Mfinanga SG, Morkve O, Kazwala RR, et al. Tribal differences in perception of tuberculosis: a possible role in tuberculosis control in Arusha, Tanzania. Int J Tuberc Lung Dis 2003;7:933-941.

30 Mfinanga SG, Morkve O, Kazwala RR, et al. The role of livestock keeping in tuberculosis trends in Arusha, Tanzania. Int J Tuberc Lung Dis 2003;7:695-704.

31 Nagai S, Wiker HG, Harboe M, et al. Isolation and partial characterization of major protein antigens in the culture fluid of Mycobacterium tuberculosis. Infect Immun 1991;59:372-382.

32 Olsen I, Wiker HG. Diffusion blotting for rapid production of multiple identical imprints from sodium dodecyl sulfate polyacrylamide gel electrophoresis on a solid support. J Immunol Methods 1998;220: 77-84.

33 Hernandez-Pando R, Jeyanathan M, Mengistu G, et al. Persistence of DNA from Mycobacterium tuberculosis in superficially normal lung tissue during latent infection. Lancet 2000;356:2133-2138.

34 Kazwala RR, Daborn CJ, Kusiluka LJM, et al. Isolation of Mycobacterium species from raw milk of pastoral cattle of the Southern Highlands of Tanzania. Trop Anim Health Product 1998;30:233-239.

35 Zumla A, Grange J. Infection and disease caused by environmental mycobacteria. Curr Opin Pulmonary Med 2002;8:166-172.

36 Cheng VCC, Yam WC, Hung IFN, et al. Clinical evaluation of the polymerase chain reaction for the rapid diagnosis of tuberculosis. J Clin Pathol 2004;57: 281-285.

37 Azov AG, Koch J, Hamilton-Dutoit SJ. Improved diagnosis of mycobacterial infections mi formalinfixed and paraffin-embedded sections with nested polymerase chain reaction. APMIS 2005;113:586-593. 